\title{
НОВЫЕ ФОРМЫ НЕЗАКОННОГО ОБОРОТА НАРКОТИЧЕСКИХ СРЕДСТВ
}

\section{NEW FORMS OF ILLICIT DRUG TRAFFICKING}

E. Vitovskaya

Summary. In the article the author addresses new forms of illicit drug trafficking, as well as some issues of countering illicit drug trafficking. The author gives statistical reports characterizing drug trafficking in Russia; Discloses a method of committing drug-related crimes using modern telecommunication technologies, including electronic payment systems. The problem of money legalization committed using crypto deserves special attention. The study concluded that the priorities for combating illicit drug trafficking through electronic payment systems should include the organization of interaction between actors engaged in countering illicit drug trafficking at both the international and State levels; Modernization of software necessary for identification of membership in crypto exchange services; Introduction of scientific research on combating illicit drug trafficking through electronic payment systems.

Keywords: drug trafficking; counteraction; Electronic payment system, crypto, legalization.

\author{
Витовская Евгения Сергеевна \\ Преподаватель, ФКОУ ВО «Кузбасский институт \\ ФСИН России», Новокузнецк \\ Jane-vit@mail.ru
}

Аннотация. В статье рассмотрены новые формы нелегального оборота наркотических средств, а также некоторые вопросы противодействия незаконному наркообороту. Автор приводит данные статистической отчетности, характеризующие наркоситуацию в России; раскрывает способ совершения преступлений наркотической направленности, при котором используются современные телекоммуникационные технологии, в том числе электронные платежные системы. Отдельного внимания заслуживает проблема легализации денежных средств, совершаемой с использованием криптовалюты. Проведенное исследование позволило сделать вывод о том, что к приоритетным задачам по противодействию нелегальному обороту наркотиков, совершаемому с использованием электронных платежных систем следует относить организацию взаимодействия между субъектами, осуществляющими противодействие незаконному обороту наркотических средств как на международном, так и на государственном уровне; модернизацию программного обеспечения, необходимого для идентификации принадлежности к сервисам по обмену криптовалют; внедрение научных исследований, посвященных противодействию нелегальному наркообороту, совершаемому с использованием электронных платежных систем.

Ключевые слова: незаконный оборот наркотиков; противодействие; электронная платежная система, криптовалюта, легализация.

реагирования в плане борьбы с нелегальным оборотом наркотиков. Это обуславливает необходимость дальнейшей разработки и поиска мер по противодействию незаконному наркообороту, совершаемому с использованием современных электронных платежных систем.

В 2019 году было зарегистрировано 190 <197 преступлений, связанных с незаконным оборотом наркотических средств и психотропных веществ, что на $20 \%$ ниже, чем в 2015 году [1]. К приведенным показателям следует относиться настороженно. Полагаем, что абсолютные показатели зарегистрированных преступлений наркотической направленности снижены за счет увеличения их латентности. Во-первых, число лиц, допускающих немедицинское потребление наркотиков достаточно высоко. По официальным данным количество наркозависимых в России составляет 500 тыс. человек [2]. Различные источники приводят другие показатели, в которых уровень первичной и вторичной заболеваемости наркоманией увеличен до 8 млн. человек [3]. Во-вторых, незаконный оборот наркотиков все чаще совершается посредством сети Интернет, с использованием современных телекоммуникационных технологий, за- 
шифрованных сетевых ресурсов, псевдонимов, кодовых слов и с соблюдением строгих мер конспирации. Современные технологии позволяют полностью исключить встречу участников сделки, а тем более с организатором, обеспечив тем самым бесконтактный способ сбыта наркотиков. В связи с этим усложняется процесс проведения оперативно-розыскных мероприятий и следственных действий, направленных на выявление фактов незаконного наркооборота. При такой преступной схеме удается привлечь к уголовной ответственности лишь рядовых участников преступных групп - курьеров и закладчиков, а выявить организаторов на сегодняшний день практически невозможно.

В последние пять лет прослеживается тенденция на снижение числа осужденных за совершение преступлений наркотической направленности. Так, в 2015 году было осуждено 116 <371 чел. (в том числе к лишению свободы на определенный срок - 50 <128), в 2016-105 <703 (45 <616), в 2017-103 <908 (43 <245), а в 2018-92 <528 (38 <441). Наряду с основной квалификацией за совершение незаконного наркооборота 0,03\% осужденных имеют дополнительную квалификацию за совершение легализации (отмывании) денежных средств, поскольку преступники совершают финансовые операции с денежными средствами, приобретенными в результате нелегального оборота наркотиков, в целях придания правомерного вида владения, пользования и распоряжения указанными денежными средствами [4]. Однако и эти показатели достаточно высоки, что приводит к мысли о необходимости целенаправленного взаимодействия по борьбе с наркотизмом. Современный незаконный оборот наркотиков представляет собой логически выстроенные технологические стадии: производство, хранение наркотиков до транспортировки к месту сбыта, создание сети оптового и розничного сбыта наркотиков, легализация доходов от наркобизнеса, осуществление мер противодействия субъектам антинаркотической деятельности.

Незаконное наркопроизводство представляет налаженную индустрию. В настоящее время расширяется деятельность подпольных лабораторий, что обусловлено целым рядом факторов: простота производства большинства видов наркотиков, доступность исходных компонентов, наличие специалистов в области химического синтеза, компактность произведенных наркотиков. Технология производства наркотиков позволяет выделить следующие виды лабораторий:

- кухонная, характеризуется ограниченной мощностью, для производства наркотиков используется кустарное оборудование, процесс изготовления наркотиков не требует участия специалистов;

- в режиме реального времени (онлайн), процесс производства наркотиков хорошо организован, требует наличия специализированного оборудования и высокой квалификации исполнителя;

- промышленная, отличается высокой производительностью наркотиков, использованием определенного оборудования, наличием специалистов, обладающих знаниями в области химического синтеза.

Расширяется методика наркопроизводства, относительная простота изготовления наркотиков позволяет использовать пошаговые алгоритмы; возможна замена исходной основы, что упрощает рецептуру; синтетические наркотики могут быть преобразованы в таблетку, что позволяет сбалансировать дозировку наркотика, облегчает их упаковку, транспортировку и хранение, а также положительно влияет на маркетинг, поскольку имеется возможность использовать логотип (форму, цвет, эмблему, голографические наклейки).

Однако реальная наркопреступность в разы больше. Контрабандный ввоз наркотиков по-прежнему остается масштабной и опасной разновидностью нелегальной трансграничной активности между странами. Наряду с известными маршрутами наркотрафика, появляются новые ответвления. Из Марокко гашиш перевозится морским и автомобильным транспортом в страны Европы, а затем перенаправляется в Российскую Федерацию. Незаконное перемещение афганского гашиша осуществляется с территории Киргизии, Азербайджана, Казахстана, Таджикистана, Узбекистана. Наркотики синтетического происхождения перемещаются из стран Европы, Латинской Америки [5, с. 5]. Кроме того, Российская Федерация обладает значительной собственной сырьевой базой для производства каннабисных наркотиков. Марихуана и гашиш, собранные на Дальнем Востоке и Северном Кавказе, в южных районах Сибири, конкурируют на наркорынке с зарубежными аналогами, поскольку произрастающая конопля содержит высокий уровень тетрагидроканнабинола.

Лидирующие позиции по транспортировке наркотиков занимают почтовые, логистические и транспортные компании. При этом используются практически все виды транспорта: воздушный, автомобильный, морской, железнодорожный.

Создание наркосети для оптового и розничного сбыта наркотических средств и психотропных веществ предполагает использование современных телекоммуникационных технологий (мобильные телефоны, планшеты, смартфоны, компьютеры), мер конспирации, зашифрованных сетевых ресурсов, электронных терминалов, используемых для перевода денежных средств и иные устройства. Наркодилеры размещают в сети Интернет объявления о продаже наркотиков. Для этого исполь- 
зуются интернет-площадки, интернет-магазины и реклама в мессенджерах (DarkNet, DarkWeb, LegalRC, Daffy Duck, Silkkitie, AS, BigRC.biz, Iklad, Silk Road, Ramp, Hansa, AlphaBay Market, Dream Market, Lambo, Telegram). К примеру, Hyrda представляет собой крупнейшую торговую площадку в даркнете, работающую на территории РФ и стран СНГ. На площадке можно приобрести наркотики, поддельные купюры, хакерские услуги, фальшивые документы, рабов и другие запрещенные товары. «Гидра» располагает более 2,5 млн. аккаунтами, за последние три года денежное обращение на площадке составило более 60 млрд. рублей. Сбыт наркотиков осуществляется преимущественно за криптовалюту. Иные торговые площадки отличаются тем, что в теневом сегменте допускается оплата наркотиков через перевод денежных средств на электронные платежные системы (Qiwi, Яндекс.Деньги) и использование кодов бирж по обмену криптовалют «Exmo», «Tether». Обменники предоставляют лицам услуги по конвертации из фиатных денег в криптовалюту с зачислением на указанный кошелек покупателя (ваучер на предъявителя). Так, в результате проведения мониторинга в русскоязычном сегменте сети Интернет выявлено более 500 сайтов, предоставляющих услуги по проведению финансовых операций с различными криптовалютами, аналогичные объявления представлены на крупных международных обменных площадках (Bestchange, KursExpert, Kurses.com.ua, Localbitoins) [5, c. 14]. Интерес вызывает тот факт, что денежные средства аккумулируются на нескольких счетах, открытых в электронной платежной системе в Qiwi, впоследствии посредством которых осуществляются финансовые операции по приобретению различных форм криптовалют в рублевом эквиваленте на биткойн, Ripple, Litecoin, Ethereum, Monero, Dash, Zcash.

За последние пять лет криптовалюта стала основным способом оплаты для лиц, продающих свой наркотовар на площадке DarkNet. Криптовалюта представляет собой виртуальные (цифровые) деньги, которые не имеют физического выражения. К основным характеристикам такой валюты относятся независимость, поскольку она не коррелирует с иной валютой, ценными бумагами, ценой на нефть; условность, данная особенность проявляется в существовании в цифровом формате и хранении в электронном кошельке; защищенность, данные не подлежат дублированию и подделке; автономность, в платежной системе отсутствует внутренний или внешний администратор; необратимость, действия по отмене, блокировке, оспариванию, принудительной транзакции невозможны, поскольку каждый этап майнинга имеет свой собственный шифр, связанный с шифром другого блока.

Обращение криптовалюты происходит в блокчейне, в открытой децентрализованной базе данных, ак- кумулирующей сведения о произведенных транзакциях. Ее открытость проявляется в том, что эти сведения дублируются на множестве серверов, расположенных на территории разных государств. В процессе майнинга (создание цепочки, посредством записи нового зашифрованного блока информации) майнеры получают монеты. После проведения финансовых операций продавец отправляет информацию покупателю о местонахождении сделанной «закладки» с наркотиком.

Каждый третий приговор по незаконному сбыту наркотиков содержит информацию о том, что он осуществлен бесконтакным способом посредством сети Интернет. К примеру, приговором Ленинского районного суда г. Воронежа осужден N за создание организованной преступной группы, основной целью которой являлся незаконный сбыт наркотиков в целях систематического извлечения постоянного дохода. N разработал бесконтактную схему сбыта наркотиков, возложив на себя роль «администратора», он создал в законспирированной части информационно-телекоммуникационной сети «Интернет» сайт интернет-магазина «Fixprice», разработал схему оплаты сбыта наркотиков в криптовалюте «Bitcoin». После чего приискал лиц, выполняющих роли «закладчиков», которые помещали наркотики в места-тайники. Назначил лицо, на роль «диспетчера», который получал адреса тайных мест хранения наркотиков и после оплаты денежных средств за приобретенные наркотики сообщал местонахождение наркотиков. Общение между участниками преступной группы велись через сеть «Тог» через псевдо-домен «Onion», что позволяло осуществлять подмену IP-адресов, использовать разовые индивидуальные логины и пароли. Кроме того, для общения использовался чат в мессенджере «Telegram», позволяющим передавать зашифрованные сообщения. Денежные средства переводились в криптовалюту «Bitcoin», которая хранилась на обезличенных счетах на интернет-ресурсах бирж данной валюты [6].

Приведенный пример показателен тем, что продемонстрирована сложная преступная схема, позволяющая исключить возможное вмешательство внешних субъектов (банка, правоохранительных органов). Следует отметить, что в такой схеме денежные средства легализуются чистыми единицами криптовалют, а денежные средства (грязные) в рублевом эквиваленте остаются на счетах обменников и криптобирж, которые не осведомлены о происхождение денежных средств. Кроме того, выплата зарплаты «операторам», «менеджеру по кадрам», «кураторам», «вербовщикам», «химикам», «складам», «курьерам», «оптово-розничным закладчикам» происходит путем обмена криптовалюты на денежные средства. Снятие денежных средств осуществляется в различных банкоматах на территории Российской Федерации, а затем наличность вносится 
на счета физических лиц либо перевозится и выплачивается наличными.

Несложно заметить, что отдельной проблемой является легализация (отмывание) доходов, полученных от незаконных операций с наркотическими средствами и психотропными веществами. Как указывалось ранее, денежные средства (грязные) аккумулируются на нескольких счетах, открытых в электронных платежных системах, таких как «Киви банк» (Qiwi кошелек) либо на счетах обменников и криптобирж. К числу таких бирж отнесены Bitstamp (Великобритания), Kraken (США), Bitfinex (Китай), Poloniex (США), Bittrex (США), LocalBitcoins (Финляндия). В случае необходимости со счетов осуществляются денежные переводы с использованием платежных систем «Wallet», «Контакт», «Вестерн Юнион», «Золотая корона», «Раураا» на подставное лицо («дроп»), после обналичивания денежные средства вкладываются в легальный бизнес или недвижимость. Кроме того, финансовые потоки преступного происхождения проходят до страны конечного инвестирования через цепочки компаний, зарегистрированных в нескольких юрисдикциях.

Следует подчеркнуть тот факт, что крупные преступные группы, занимающиеся незаконным наркооборотом с использованием телекоммуникационных сетей, в своем большинстве характеризуются транснациональным характером деятельности, вследствие чего возникает проблема определения территориальной юрисдикции государств.

Несмотря на то, что привлечение к уголовной ответственности лиц, предоставляющих услуги по обмену криптовалют с целью легализации наркодоходов относится к числу важных проблем силовых ведомств, все же практика выявления, документирования и расследования преступлений, предусмотренных ст. $174^{1}$ Уголовного кодекса РФ, совершаемых с использованием криптоактивов при расчетах за наркотические средства и психотропные вещества встречается. На наш взгляд, положительным моментом следует считать изменение в Постановление Пленума Верховного Суда РФ от 07.07.2015 № 32 «О судебной практике по делам о легализации (отмывании) денежных средств или иного имущества, приобретенных преступным путем, и о приобретении или сбыте имущества, заведомо добытого преступным путем», которое признает криптовалюту средством легализации преступных доходов. Подобное изменение позволит совершенствовать практику применения законодательства о противодействии легализации преступных доходов.

В качестве примера можно привести уголовное дело, возбужденное по факту сбыта «бесконтактным спо- собом» наркотиков через онлайн-магазин Daffy Duck. Преступная схема предусматривала оплату приобретенных наркотиков через электронную платежную систему с конвертацией в криптовалюту «Bitcoin». Bce финансовые операции осуществлялись через биржу Exmo.com, которая способствовала выведению денежных средств на подставные расчетные счета, с целью обналичивания. Проведенные следственные действия позволили установить банковские карты и электронные платежные счета, с помощью которых происходил обмен на криптовалюту, учетную запись на площадке «Ехто», биткойн кошельки, финансовые операции по обмену криптовалюту на рублевый эквивалент. Членам преступной наркогруппировки назначено наказание в виде лишения свободы сроком на 13 лет, два из которых за отмывание денежных средств [7].

Известно, что борьба с легализацией денежных средств первоначально складывалась в связи с торговлей наркотиками, поэтому представители наркобизнеса активно используют возможности «теневой» финансовой инфраструктуры, предоставляющей услуги по перераспределению и отмыванию денежных средств. Анализ финансовых операций показывает, что деятельность таких профессиональных посредников носит транснациональный характер и, следовательно, во многом определяет географию нелегальных финансовых потоков. Значительная часть транзакций осуществляется по типу «хавала», «хунди», «теневого бакинга», через службы денежных переводов, предоставляющих услуги по переводу и получению денежных средств, а также по осуществлению расчетов путем торговли и взаимозачетов [8, с. 7]. Популярность международных служб денежных переводов зачастую связана с использованием новых способов платежей, в том числе перевода мобильных денег.

Особую общественную опасность представляет коррупция, связанная с наркопреступностью. Деятельность преступных групп, прежде всего, направлена на приобретение коррумпированных связей, путем взяточничества и подкупа должностных лиц. Правоприменительная практика показывает, что коррумпированное должностное лицо выполняет не разовые «просьбы» преступности, оно состоит у нее на службе. В настоящее время все чаще встречаются факты коррупционного поведения среди субъектов, вовлеченных в деятельность по противодействию незаконного наркообороту. Однако данные официальной статистики не в полной мере отражают реальную ситуацию. Очевидно, что без покровителей в государственных структурах наркопреступность не может существовать.

В связи с появлением новых форм незаконного наркооборота, совершаемого с использованием элек- 
тронных платежных систем приоритетными задачами по противодействию нелегальному обороту наркотических средств видятся следующие:

1. Организация взаимодействия между субъектами, осуществляющими противодействие незаконному обороту наркотических средств по вопросу получения информации об операциях по выводам денежных средств на банковские карты, а также информации по конкретным операциям с участием интересующих банковских карт или расчетных счетов различных электронных платежных систем и кошельков различных криптовалют.

2. Усовершенствование программного обеспечения, необходимого для идентификации принадлежности к сервисам по обмену криптовалют.

3. Создание межгосударственных комиссий по обмену информацией о преступных организациях, осуществляющих незаконный оборот наркотических средств, в том числе с использованием электронных платежных систем.

4. Организация взаимодействия между правоохранительными органами, привлекающими специалистов для выявления и пресечения деятельности по незаконному обороту наркотиков в сети Интернет, анализа текущего состояния наркопреступности в киберпространстве, идентификации лиц, причастных к незаконному обороту наркотических средств с использованием сети Интернет, осуществления блокировки Интернет-ресурсов и серверов, выявления международного наркотрафика.

5. Внедрение научных исследований, посвященных противодействию незаконному обороту наркотических средств, совершаемому с использованием электронных платежных систем.

\section{ЛИТЕРАТУРА}

1. Основные показатели по преступности [Электронный ресурс] // Официальный сайт Федеральной службы государственной статистики России. Режим доступа: http: www.gks.ru.doc (дата обращения: 01.06.2020).

2. Основные показатели здоровья населения [Электронный ресурс] // Официальный сайт Федеральной службы государственной статистики России. Режим доступа: http://www.gks.ru.doc (дата обращения: 01.06.2020).

3. Принудительная госпитализация наркоманов [Электронный ресурс] // Официальный сайт Независимого информационного агентства «Interfaх». Режим доступа: https://www.interfax.ru/russia/357377 (дата обращения: 01.06.2020).

4. Сводные статистические сведения о судимости в России [Электронный ресурс] // Официальный сайт Судебного департамента при Верховном суде РФ. Режим доступа: http://www.cdep.ru (дата обращения: 01.06.2020).

5. Кромова, А. Я. Контрабанда наркотиков (статья 2291 УК РФ): монография.— М.: Проспект, 2014.— 136 с.

6. Приговор по делу № 1-181/2017 от 14.08.2017 в обвинении N [Электронный ресурс] // Официальный сайт Ленинского районного суда г. Воронежа. Режим доступа: https://sudact.ru/regular/doc/26039v5DHb1W (дата обращения: 01.06.2020).

7. Виртуальные активы получили криминальное определение: Верховный суд признал криптовалюту одним из средств отмывания денег [Электронный ресурс] // Официальный сайт Центрального районного суда г. Тольятти. Режим доступа: http://centralny.sam.sudrf.ru/modules.php (дата обращения: 01.06.2020).

8. Роль систем «Хавала» и других аналогичных услуг в отмывании денег и финансировании терроризма. — М.: Группа разработки финансовых мер по борьбе с отмыванием денег (ФАТФ), 2013.- 104 с.

(c) Витовская Евгения Сергеевна ( Jane-vit@mail.ru). 